\title{
HOMENAJE A UN GRAN MAESTRO E HISTORIADOR: JUAN CARLOS GARAVAGLIA. LECCIONES Y TÓPICOS PARA LA AGENDA HISTORIOGRÁFICA EN COSTA RICA TRIBUTE TO A GREAT HISTORIAN AND PROFESSOR: JUAN CARLOS GARAVAGLIA. LESSONS AND TOPICS FOR THE HISTORIOGRAPHIC AGENDA IN COSTA RICA
}

\author{
Pablo Augusto Rodríguez Solano*
}

\begin{abstract}
Resumen: El siguiente artículo es un homenaje al doctor Juan Carlos Garavaglia, quien falleció el 15 de enero de 2017 en Francia. La exposición comienza presentando su contexto y vida, como marco para comprender a la persona, más allá del historiador, haciendo un repaso rápido de su vida y su forma de ser. Esto nos permite acercarnos a su producción a partir del principal rasgo de su personalidad, su humanidad, siempre presente en su obra, impulsándolo a rescatar a los individuos como actores de la historia, que en su nivel relacional son los que crean y nutren a las instituciones, superando con ello las explicaciones superestructurales en su aproximación a la disciplina. Finalmente, revisaremos algunos de sus aportes, de los cuales se rescatan algunas de las relevantes lecciones para una de las posibles agendas de investigación en Costa Rica.
\end{abstract}

Palabras claves: historia; historiografía; Juan Carlos Garavaglia; Costa Rica.

Abstract: This article is a tribute to Juan Carlos Garavaglia, who died on January 15, 2017, in France. It begins by presenting the context of his life, as frame to

* Costarricense. Doctor en Historia por la Universidad Pompeu Fabra (UPF) de Barcelona, profesor de la Escuela de Estudios Generales de la Universidad de Costa Rica, investigador en el Centro de Investigación en Identidades y Cultura Latinoamericana (CIICLA) de la UCR y del Grupo de Investigación en Imperios, Metrópolis y Sociedades Extraeuropeas de la UPF (GRIMSE). Fue parte del equipo de investigadores en el proyecto State Building in Latin America, dirigido por el doctor Juan Carlos Garavaglia entre el 2009 y 2014. Correo electrónico: pablo.rodriguez_s@ucr.ac.cr ORCID: https://orcid.org/0000-0001-7489-0067 
understand the person, beyond the historian, making a quick review of his life and personality. This allows us to approach his production from his main feature, his humanity, always present in his work, it was a feature that always pushed him to rescue people as actors of history, who at their relational level are those who create and nourish institutions, surpassing with this a superstructural approach to the discipline. Finally, we will review some of his contributions, from which to rescue some of the main lessons of his work for a possible research agenda in Costa Rica.

Keywords: History; Historiography; Juan Carlos Garavaglia; Costa Rica.

"Los hombres se parecen más a su tiempo que a sus padres". ${ }^{1}$

\section{Imagen utilizada en la tarjeta de cumpleaños número 67 de Juan Carlos Garavaglia}

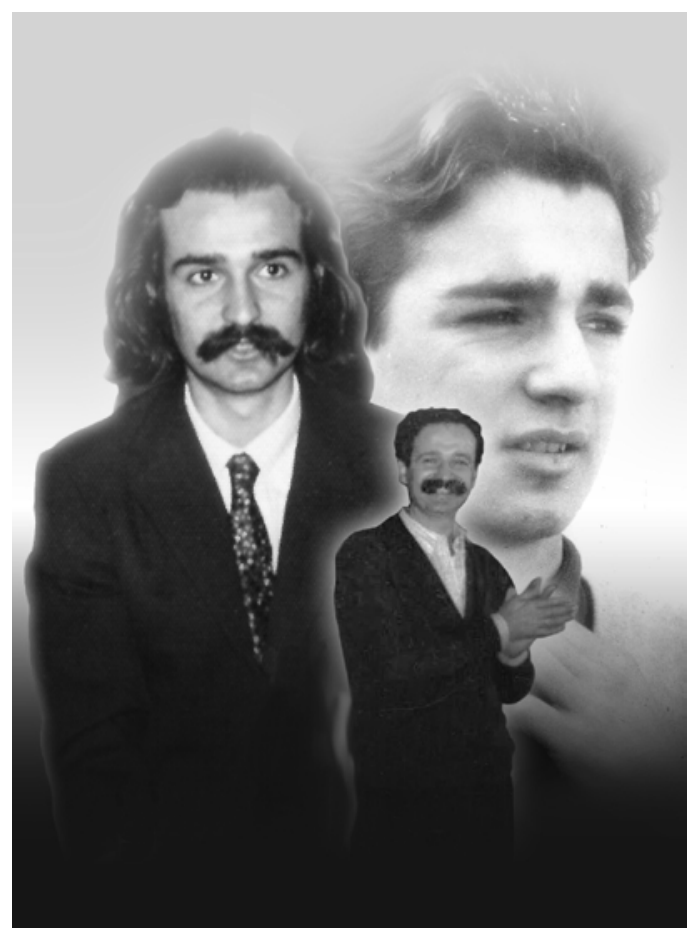

Fuente: Creación propia a partir de fotografías cedidas por Elisa Casselli.

1 Marc Bloch, Apología para la historia o el oficio del historiador (México, D.F.: Fondo de Cultura Económica, 2001), 32. 


\section{Advertencia}

Antes de continuar, debo disculparme con el lector, pues no solo he de escribir en primera persona en distintos momentos y para referirme a eventos y personajes, sino que podría ser imposible escribir estas páginas sin utilizar anécdotas e historias del tiempo que compartí con Juan Carlos Garavaglia. Esto es relevante para la narrativa que se pretende, porque resulta imposible transmitir el sentido de la obra de Gara, como lo llegamos a conocer, sin describir su personalidad y tratar de acercar al lector a la forma en que este reconocido porteño se acercaba a la vida y a las personas. No puedo pretender tampoco hacer un trabajo tan profundo como lo han hecho ya muchos de quienes lo llegaron a conocer de manera más profunda a lo largo de su vida, entre ellos sus amigos Raúl Fradkin, Jorge Gelman o Carlos Marichal. ${ }^{2}$ Como parte de este acercamiento, invitamos a visitar el sitio de homenaje que se le hizo a Juan Carlos, por iniciativa de muchos de sus amigos y colegas, ${ }^{3}$ así como a leer las memorias que él mismo escribió y salieron publicadas en el 2015. ${ }^{4}$ Dicho esto, el presente no es un trabajo exhaustivo de revisión bibliográfica de su extensa producción, ${ }^{5}$ sino un ejercicio para

2 Entre las obras que destacan su carácter y obra pueden verse: Raúl Fradkin y Jorge Gelman, “Juan Carlos Garavaglia, hasta siempre", Anuario IEHS (Argentina) 32, n. 1 (2017): 7-18, URL: http://anuarioiehs. unicen.edu.ar/Files/2017\%201/01\%20Anuario\%20IEHS\%2032(1)\%20o.Fradkin\&Gelman.pdf; Jorge Gelman, Raúl Fradkin, Judith Farberman y Alejandro Rabinovich, "Homenaje a Juan Carlos Garavaglia", Boletín del Instituto de Historia Argentina y Americana "Dr. Emilio Ravignani” (Argentina) tercera series, n. 47 (julio-diciembre, 2017): 11-30, en: https://www.unicen.edu.ar/iehs/homenaje/files/testimonios/Homenaje\%20Ravignani.pdf; José Mateo, "Juan Carlos Garavaglia: un historiador genial, generoso, guapo y compadrón”, Revista de Estudios Marítimos y Sociales (Argentina) año 9, n. 10 (julio-diciembre, 2016), en: https://estudiosmaritimossociales.org/archivo/rems-10/presentacion/. Algunas obras que revisan su legado, pensamiento y aportes pueden verse a los siguientes: Darío Barriera, "Pequeñas anécdotas sobre las instituciones'. Juan Carlos Garavaglia, apuntes sobre su concepción de las instituciones (entre oralidad y escritura)", Anuario IEHS (Argentina) 33, n. 1 (2018): 207-221, en: http://anuarioiehs.unicen.edu.ar/resumenes/2018/9\%20JUAN\%20CARLOS\%20GARAVAGLIA,\%20APUNTES\%20SOBRE\%20SU\%20 CONCEPCI\%C3\%93N.html; Jorge Gelman, "Juan Carlos Garavaglia y la historia económico-social de América Latina. Algunas lecciones de historia y de vida”, Prohistoria (Argentina) vol. 28 (2017): 281-287, en: http://www.scielo.org.ar/scielo.php?script=sci abstract\&pid=S1851-95042017000200015; Raúl Fradkin, "Indicios y conjeturas: la formación de un historiador original", Prohistoria (Argentina) año XX, n. 28 (diciembre, 2017): 257-275, en: https://dialnet.unirioja.es/descarga/articulo/6333082.pdf; Carlos Marichal, "Testimonio de Juan Carlos Garavaglia (1944-2017): sus contribuciones a la historia económica y social del México colonial”, Historia Mexicana (México) 68, n. 2 (octubre-diciembre, 2018): 889-903, DOI: http://dx.doi.org/10.24201/hm.v68i2.3759. Otras obras hacen un excelente recorrido por la vida de Juan Carlos Garavaglia, puede verse, entre estas: Mariano Martín Schlez y Stella Marís Grenat, "Militante total: Juan Carlos Garavaglia en la terrorífica noche bahiense", Americanía. Revista de Estudios Latinoamericanos (Sevilla, España) 8 (julio-diciembre 2018): 155-195, en: https://www.upo.es/revistas/index.php/americania/article/view/3801. La cantidad de artículos es imposible de registrar en su totalidad, en vista que el homenaje a Juan Carlos se extendió a las Jornadas Interescuelas de Mar del Plata y actividades del Instituto de Historia Argentina y Americana “Dr. Emilio Ravignani”, así como números especiales de revista, como por ejemplo: http://www.scielo.org.ar/scielo.php?script=sci_arttext\&pid=S1851-95042017000200001.

3 https:/www.upo.es/revistas/index.php/americania/article/view/3801.

4 Juan Carlos Garavaglia, Una juventud en los sesenta (Rosario, Argentina: Prometeo, 2015).

5 La cual abarca más de 90 títulos diferentes a lo largo de 50 años de acercamiento a la disciplina. En el siguiente enlace puede verse una recopilación de algunos trabajos de Juan Carlos Garavaglia, recopilados por Dialnet, estos se encuentran descargables: https://dialnet.unirioja.es/servlet/autor?codigo=354513. 
acercar al lector a la persona y al historiador que fue Juan Carlos Garavaglia, como recurso para advertir las lecciones que podemos extraer hoy a dos años de su muerte. Por lo tanto, trataré de hacerle justicia a la memoria de tan entrañable amigo. Los recuerdos, sacados de la memoria, pueden no ser prístinos y son mediados por el tiempo, pero tratan de hacer un retrato del sentimiento y las lecciones que transmitió, me disculpo de antemano por la completa incapacidad de traducir el incomparable estilo de Gara.

\title{
Un hombre y su contexto
}

\begin{abstract}
"Había que arremangarse y trabajar en primera persona. Fue así como teché, puse chapas, cavé zanjas, aprendí a revocar, a pintar, etc. [...] La alegría de ver terminada una obra y comprobar cómo los vecinos -en realidad, las vecinas...- tenían que caminar mucho menos para buscar agua, fue uno de los escasos momentos de puro placer y satisfacción que gocé en silencio". 6
\end{abstract}

Las diferentes reseñas hechas permiten comprender lo difícil de separar al hombre de su contexto, en el cual se construyó su personalidad y se desarrollaron sus ideas. La vida de Juan Carlos Garavaglia moldeó su compromiso social y la aproximación a la historia, siendo patente en sus trabajos, con una producción que posee trazos inequívocos de su acercamiento a la sociedad. Su militancia política en la montonera argentina, en tiempo de compleja violencia política y social en su país, marcó de manera profunda la forma de concebir los fenómenos sociales y su comprensión del papel de la historia. Este apartado es un intento por dar una breve reseña de su vida, como marco para comprender las lecciones que nos deja. Se basa enteramente en las reseñas que le han hecho desde el 2017, año de su muerte, así como la lectura de sus memorias, las cuales publicó en el 2015.

Juan Carlos nació en Pasto, Colombia, en 1944, algo que nos hizo saber desde los primeros días que lo conocimos en Barcelona en el 2009. Era una persona de gran amabilidad y un compromiso absoluto con su profesión, la cual comenzó a estudiar tras haber abandonado la carrera de derecho en 1966, año de terrible memoria para Argentina, ya que empezaba la dictadura de Onganía, lo que también marcaría sus inicios en la acción política. En sus memorias recuerda que fue en 1965, en unas charlas de José Luis Romero y Tulio Halperín Donghi cuando supo que "lo que deseaba más que nada era 'ser historiador' y no 'estudiar historia". ${ }^{7}$ Esta distinción parece de la mayor importancia, especialmente para quien hubiera tenido la oportunidad de ver el nivel de compromiso con el que asumía su profesión.

6 Garavaglia, Una juventud..., 176.

Ibid, 117. 
En estos años universitarios, entre 1963 y 1969, fue que Juan Carlos se acercó a dos de los aspectos que definirían su quehacer y desarrollo intelectual. Por un lado, su trabajo en la librería y editorial de Jorge Álvarez, que Raúl Fradkin ha caracterizado como un centro cultural del Buenos Aires de la época; ${ }^{8}$ mientras que, por otro lado, sus primeros acercamientos con la militancia política, que llevarían a su arresto en 1968, en la prisión de Ezeiza durante unas semanas, donde impartiría clases de Historia Argentina a los presos. Esta época resultó de gran valor porque en ella comenzó a tejer lazos importantes con personajes de la época, acercándose a figuras como Silvio Frondizi, entre otros que conoció en la cárcel y a los cuales dedicaría su ponencia del congreso americanista de $1972 .{ }^{9}$

Se graduó como licenciado en Historia en $1970 .{ }^{10}$ Fue a partir de ese año que encontraría otra de sus pasiones, una de las cuales llegaría a definir su profesión: la edición de libros. Fundó junto a Enrique Tandeter la editorial Signos, que un par de años más tarde se integraría a Siglo XXI. No obstante, apunta Raúl Fradkin, la labor de esta editorial fue muy prolífica con no menos de 20 títulos, algunos de los cuales se terminarían de publicar bajo el sello de Siglo XXI. ${ }^{11}$ En esta labor es que tendría contacto con autores de gran importancia, los que todavía recordaba con cariño muchos años después, como Maurice Dobb y algunos otros de los marxistas británicos. Paralelamente, con 24 años, Juan Carlos comenzaría a impartir lecciones en la Cátedra de Introducción a la Historia de la UBA, como asistente de segunda ad honórem.

Ya desde esta época demostró algo que sería patente a todos los que lo conocieron: su capacidad de administrar su trabajo entre una gran multitud de tareas. Con qué tiempo lograba Juan Carlos balancear la dirección de proyectos, la edición de libros y tesis, dar clases, ir al archivo y otras muchas ocupaciones. En aquella época, todas estas labores académicas se combinaban adicionalmente con la militancia política, la que progresivamente iba tomando más tiempo, como indica en sus memorias:

8 Fradkin, "Indicios y conjeturas...", 262-263.

9 Esta ponencia sería publicada posteriormente en 1975, véase: Juan Carlos Garavaglia, "Las actividades agropecuarias en el marco de la vida económica del pueblo de indios de Nuestra Señora de los Santos Reyes Magos de Yapeyú, 1768-1806”, en: Hacienda, latifundios y plantaciones en América Latina, (coord.) Enrique Florescano (Buenos Aires, Argentina: Siglo XXI; CLACSO, 1975): 464-486, disponible en: http://biblioteca.clacso.edu.ar/ar/libros/historico/floresca.pdf.

10 Juan Carlos Garavaglia, El comercio virreinal: 1779-1784 (Tesis de Licenciatura en Historia, Universidad de Buenos Aires, 1970). El documento completo puede encontrarse en el repositorio de la UBA: http://repositorio.filo.uba.ar/bitstream/handle/filodigital/4206/uba_ffyl_t_1970_se_Garavaglia. pdf? sequence $=3 \&$ is Allowed $=\mathrm{y}$.

11 Fradkin, "Indicios y conjeturas...", 267-268. También indica que la absorción de Signos por Siglo XXI no significó el fin de la experiencia editorial de Juan Carlos, ya que este siguió colaborando en esa editorial, integrando además parte importante del trabajo en Cuadernos Pasado y Presente de Córdoba, donde entró en contacto con figuras como Carlos Sempar Assadourian o Juan Carlos Chiaramonte. 


\begin{abstract}
"Como se puede ver, me hallaba a dos -y hasta tres-aguas; la política, la editorial -mi medio de vida- y los primeros escarceos en la profesión del historiador. No creía yo entonces que fuera contradictorio, sino todo lo contrario [...] Finalmente, la acción política acabó 'comiéndose' todo, pero no me arrepiento en lo más mínimo por el hecho de haberlo intentado". ${ }^{2}$
\end{abstract}

En 1971 volvió a entrar a la prisión de Devoto durante unos días. Su activismo político hizo que terminara siendo expulsado de la facultad, pero nada de esto detuvo su trabajo. En 1973, con 27 años, llega a un momento clave de su vida. En ese año se publica el número 40 de Cuadernos de Pasado y Presente, sobre Modos de Producción, es nombrado interventor en la Universidad Nacional del Sur en Bahía Blanca y decide solicitar su encuadramiento en los montoneros. ${ }^{13}$ Hasta ese momento la experiencia de Juan Carlos había sido la de un responsable barrial en la organización montonera, por lo que actuaba como intermediario entre la organización central -la Orga-y los militantes de los barrios, pero el encuadramiento significaba entrar en el cuerpo armado de los montoneros.

En 1975 la situación política se agravó debido a la progresiva victoria de los sectores más extremos de la derecha peronista, que se habían desatado completamente desde la muerte de Perón en 1974. Habían invadido poco a poco los espacios universitarios, atacando los presupuestos y la organización interna, excluyendo y persiguiendo a todos los que a ojos de sus líderes eran "marxistas peligrosos". Juan Carlos, que desde fines de 1974 había abandonado a los montoneros, no fue una excepción. Tuvo que retirarse -fue expulsado- de la Universidad de Bahía Blanca, pasando un tiempo escondido en Buenos Aires, haciendo trabajo de archivo, hasta que en 1976 la situación política fue insoportable y tuvo que huir. Llegó a París ese mismo año, donde ingresó a la École des Hautes Etudes en Sciences Sociales (EHESS) y desarrolló su tesis de doctorado con Ruggiero Romano como su director entre 1976 y 1979.

El período entre 1966 y 1976 había marcado profundamente su acercamiento a la enseñanza y al trabajo colectivo. Su compromiso social lo había hecho parte de una generación que creía en la renovación de la democracia argentina, que demandaba mejoras políticas, y que, a nivel de la universidad, “querían replantear la relación tradicional 'entre profesor y discípulo', realizar una tarea teórico-práctica que lograra vincular ciencia y política de un modo nuevo y alternativo a los del 'cientificismo' y el 'populismo' y articular la lucha docente y estudiantil". ${ }^{14}$ Tal vez por ello, especula el mismo Fradkin, su objetivo fue siempre influir en la formación de la juventud hasta sus últimos días.

12 Garavaglia, Una juventud..., 163.

13 Sobre su tiempo en Bahía Blanca se puede ver Schlez y Grenat.

14 Fradkin, "Indicios y conjeturas...", 266. 
La tesis de doctorado de Juan Carlos de 1979, titulada La production et la commercialisation de la Yerba Mate dans l'espace péruvien: XVIe-XVIIIe siècles,$^{15}$ representó la cristalización de un interés que comenzó, según Jorge Gelman y Raúl Fradkin, con la traducción del libro de León Pomer sobre Paraguay, ${ }^{16}$ un tema al que volvería en diferentes momentos de su vida y que daría importantes réditos en su explicación de los complejos fenómenos de América Latina. Esta tesis sería después publicada con el título Mercado interno y economía colonial. Tres siglos de historia de la yerba mate, influyendo profundamente en el campo historiográfico latinoamericano de esas décadas. ${ }^{17}$

A partir de 1980 Juan Carlos se incorporó a la Universidad Autónoma Metropolitana (UAM), en México, en un momento en el cual llegaba gran cantidad de exiliados de las dictaduras latinoamericanas a ayudar en la renovación del espacio intelectual universitario. Carlos Marichal recuerda a Juan Carlos Garavaglia como un tornado que apareció en el espacio mexicano en esos años. ${ }^{18}$ Era un momento muy excitante para el trabajo académico, el cual Juan Carlos aprovechó para tomar por asalto los archivos coloniales, en una titánica labor de organización y revisión, que lo llevó a profundizar en los fenómenos del intercambio, el comercio y las alcabalas. Esta labor concluyó con sendos trabajos, algunos de la mano con su gran amigo Juan Carlos Grosso, sobre el municipio de Tepeaca, ${ }^{19}$ así como sobre las alcabalas. ${ }^{20}$ Trabajos que inspiraron a toda una generación de historiadores en México, que a partir de la década de 1990 tendrían mucha influencia en el medio académico.

En 1985 vuelve a Argentina tras años de exilio. A propósito de ese momento, recuerdo una anécdota que nos contó con gran emoción. Cuenta que se bajó del avión y realizó los trámites de migración y demás, al salir del aeropuerto tomó un taxi, quien haya ido a Buenos Aires sabrá que esta es una experiencia y que la

15 Juan Carlos Garavaglia, La producción y comercialización de la Yerba Mate en el espacio peruano: siglos XVI-XVIII (Tesis de Doctorado en Historia, École des Hautes Etudes en Sciences Sociales, Francia, 1979). Esta tesis se encuentra dentro del catálogo de tesis del Centro de Investigaciones Históricas de América Central (CIHAC), UCR, como Tesis \# 2.

16 León Pomer, La Guerra del Paraguay. Estado, política y negocios (Buenos Aires, Argentina: Centro Editor de América Latina, 1968).

17 Juan Carlos Garavaglia, Mercado interno y economía colonial. Tres siglos de historia de la yerba mate (México, D.F.: Enlace Grijalbo, 1983).

18 Marichal, "Testimonio...," 1.

19 Juan Carlos Garavaglia y Juan Carlo Grosso, Puebla desde una perspectiva microhistórica. La villa de Tepeaca y su entorno agrario: población, producción e intercambio (17401870) (México: Claves Latinoamericanas, Universidad Autónoma de Puebla. Argentina: Universidad Nacional del Centro, 1994).

20 Juan Carlos Garavaglia, "Le regioni della Nueva España nel periodo borbonico: un'analisi cuantitativa, 1778-1809”, Rivista Storica Italiana, 99, n. 3 (1987); Juan Carlos Garavaglia y Juan Carlos Grosso, La región de Puebla y la economía novohispana: las alcabalas en la Nueva España, 1776-1821 (México: Instituto de Investigaciones "Dr. José María Luis Mora”, 1996); Juan Carlos Garavaglia y Juan Carlos Grosso, "De Veracruz a Durango: un análisis regional en la Nueva España borbónica", Siglo XIX. Revista de Historia, 2, n. 4 (1987): 9-52. 
conversación con un taxista puede resultar una experiencia turística surrealista. En el camino, tras una buena conversación sobre cualquier cosa, el taxista se dio cuenta que Juan Carlos llegaba a casa desde el exilio y que tenía 10 años de no tocar suelo argentino. Con mucha emoción y casi con lágrimas el taxista le dijo "este viaje sale gratis". Juan Carlos, que no era aficionado al nacionalismo, dijo que la emoción lo embargó y las lágrimas brotaron.

A partir de 1986 y hasta 1991 ingresó a la Universidad de Tandil, momento en que siguió trabajando los textos que publicó con Grosso y que ya hemos mencionado. Pero también realizó la investigación que culminaría en uno de sus libros más reconocidos, titulado Pastores y labradores, que se publicaría en español en 1999, y en francés como Les hommes de la Pampa en el año 2000. ${ }^{21}$ En 1991 se le dio el puesto de Directeur d'Études en la EHESS, a partir de ese momento su contacto con la academia de París y su experiencia de archivo lo acercan progresivamente al tema del poder, la construcción de instituciones que regulaban la vida de los campesinos que durante años había estudiado. ${ }^{22}$ Esto se orientó principalmente al estudio de la justicia, pero con el tiempo abarcó la fiscalidad y su institucionalidad, las fuerzas de guerra y otras instituciones.

Cada nuevo tema lo llevó con más ahínco a tratar de alcanzar explicaciones más generales, que permitieran comprender el tema del Estado en América Latina y sus procesos. Como parte de ese esfuerzo inicial se puede contar con el texto desarrollado con Juan Marchena, América Latina. De los orígenes a la independencia. ${ }^{23}$ Ya en el 2008 se muda a Barcelona, previendo su jubilación de la EHESS, con el objetivo de reunir un equipo para trabajar en la Universidad Pompeu Fabra, para desarrollar un proyecto titulado State Building in Latin America, como parte de un Grant concedido por el Consejo Europeo de Investigación, el cual sintetizó muchos de los esfuerzos que desarrolla a partir de esa fecha en adelante. ${ }^{24}$

21 Barriera, 210. Juan Carlos Garavaglia, Pastores y labradores en Buenos Aires. Una historia agraria de la campaña bonaerense (1700-1830) (Buenos Aires, Argentina: De la Flor, 1999); Juan Carlos Garavaglia, Les hommes de la Pampa, Une histoire agraire de la Campagne de Buenos Aires, 1700-1830 (Paris, Francias: Éditions de l'EHESS, 2000). Un artículo previo ya mostraba las intenciones de Garavaglia y su crítica a la historia nacionalista que sostenía el mito del Gaucho, ver Juan Carlos Garavaglia, "¿Existieron los gauchos?", Anuario IEHS, n. 2 (1987): 42-52, en: http://anuarioiehs.unicen.edu.ar/Files/1987/004\%20 -\%20Garaviglia\%20Juan\%20CArlos\%20-\%20Existieron\%20los\%20gauchos.pdf.

22 Juan Carlos Garavaglia y Jorge Gelman, "Mucha tierra y poca gente: un nuevo balance historiográfico de la historia rural platense (1750-1850)", Historia agraria: Revista de agricultura e historia rural, n. 15 (1998): 29-50, en: http://www.historiaagraria.com/es/numeros/juan-carlos-garavaglia-jorge-gelman-mucha-tierra-y-poca-gente-un-nuevo-balance-historiografico-de-la-historia-rural-platense-1750-1850; Juan Carlos Garavaglia, Poder, conflicto y relaciones sociales (Rosario, Argentina: Homo Sapiens, 1999); Juan Carlos Garavaglia, "Alcaldes de la Hermandad et juges de paix à Buenos Aires (XVIII'-XIX" siècles), Études rurales, n. 149-150 (1999): 99-110, en: https://www.persee.fr/doc/rural_0014-2182_1999_num_149_1_4707.

23 Juan Carlos Garavaglia y Juan Marchena, América Latina. De los origenes a la independencia (Barcelona, España: Editorial Crítica, 2005).

24 Para más información sobre el proyecto puede refiérase: http://statebglat.upf.edu/. 
A lo largo de los años, su trabajo en distintos artículos y libros resultó en importantes aportes a la historia colonial, no solo del Río de la Plata, que colocó de nuevo en el contexto latinoamericano, sino también del resto de la región. Con cada nuevo paso definió las características más evidentes de los mercados internos y la cultura material del período, pero por sobre todo desmintió las falsedades de una historiografía tradicional que atribuía el papel principal en esos mercados a los hacendados y comerciantes. Su labor al redescubrir a los campesinos, a las personas comunes, que movían la sociedad, a través de su análisis del mercado para la reorganización del espacio social, se puede contar como uno de sus aportes más relevantes. Ya más adelante, esta preocupación se amplió para incluir además las fuerzas institucionales del Estado -justicia, represión/guerra y recaudación-. Según Darío Barriera, Garavaglia pretendía mostrar a las instituciones como "un artificio, [donde] lo relacional no es anterior, sino temporalmente, al menos coetáneo en lo constituyente: las relaciones constituyen las instituciones". ${ }^{25}$

\title{
Un gran maestro: características del historiador y el ser humano.
}

Fue probablemente en el 2009, a mi llegada a la urbe catalana, cuando Juan Carlos me contó una anécdota, ante la cual no pude contener la risa y aún hoy me causa una combinación de alegría y nostalgia, tras 10 años de ese momento:

\begin{abstract}
"Fue en 1991, cuando me nombraron director de estudios en la École, que me pidieron, por ser costumbre de todos los que se incorporan, dar una lección inaugural. Me preparé lo mejor que pude, leí hasta el cansancio y me presenté, pero una vez sobre el podio noté al público... ahí, a la par de Le Goff, se veía a Nora y más allá a Bourdieu, entre otros. Comencé a sudar profusamente, ¡sentí los nervios de alguien que iba a dar un discurso ante semejante público! Los miré, ellos me miraron esperando, y dije de repente... 'Estoy honrado de estar acá presente, siento que doy un discurso ante mi biblioteca". ${ }^{26}$
\end{abstract}

Esa podría ser una de las más entrañables y queridas facetas del maestro, la capacidad de mantener un gran sentido del humor que terminaba desarmando a su público, arrancando sonrisas cómplices y creando cercanía. Frente a mí, un estudiante de historia de Costa Rica, sin experiencia, se encontraba uno de los historiadores más conocidos y respetados de América Latina; sin embargo, con sus formas, tan humanas y cálidas, había logrado reducir mis nervios y permitirme sentir bienvenido. El motivo de la anécdota, al igual que muchas otras que escuchamos en nuestra estadía, y una multitud que se han compartido en homenajes y artículos, es evidenciar su capacidad para crear un gran ambiente

25 Barriera, 216.

26 Es una anécdota contada por Juan Carlos durante las reuniones del programa en el 2009. 
de trabajo entre quienes lo conocieron. Algo que Darío Barriera ha sintetizado de manera maravillosa, señalando que Juan Carlos Garavaglia era y seguirá siendo en el recuerdo de quienes lo conocieron un verdadero maestro en el arte de la "enseñanza de proximidad". ${ }^{27}$

Derivada de esa capacidad para crear un ambiente agradable, una segunda característica fue su constante búsqueda por colaborar, una sinergia continua con otros historiadores, científicos sociales y especialistas, la cual se manifestó en la impresionante cantidad de trabajos colectivos que podemos leer hoy. ${ }^{28}$ Porque no solo se destacó por su increíblemente detallado y profundo quehacer individual, que hizo uso exhaustivo de las fuentes de archivo, así como gala de un minucioso análisis. También sobresalió por el trabajo colectivo, que reunió en gran cantidad de libros, con la participación de distintos investigadores para discutir las temáticas que desde muy temprano en su carrera ya se perfilaban. De lo cual pueden dar reconocimiento el gran coro de historiadores y otros científicos sociales que han escrito y lamentado sobre la muerte de Gara.

Pero fue, sin dudarlo, su inacabable e inquieta curiosidad lo que lo llevó a generar incontable cantidad de preguntas, una de sus características más apreciadas. Algunas de las cuales todavía aguardan que los investigadores jóvenes se acerquen, como agendas de trabajo para construir una historia de América Latina, comprometida con la comprensión del pasado para entender mejor el presente. Esto, como lo han señalado Jorge Gelman y Raúl Fradkin, se transformó para Garavaglia en una forma cercana de compromiso, en una manera de amar, "y él lo sabía y lo enseñaba no mediante discurso, sino por medio de una práctica tan intensa como prolongada y persistente". 29

Reconocido como un historiador económico sobre la América Hispana del período colonial, en realidad su enfoque fue el de un historiador social que puso

27 Barriera, 212.

28 En esto también se combinó su experiencia editorial y su experiencia en distintos lugares de América Latina. Comenzando con su famoso número 40 de los Cuadernos de Pasado y Presente, dedicada a los Modos de Producción, véase: Juan Carlos Garavaglia (editor), "Modos de producción en América Latina", Cuadernos de Pasado y Presente, n. 40 (1973). Pero también podemos citar: Juan Carlos Garavaglia y Raúl Fradkinv (editores), En busca de un tiempo perdido. La economía de Buenos Aires en el país de la abundancia (1750-1865) (Buenos Aires: Prometeo libros, 2005); Juan Carlos Garavaglia y Jean-Frédéric Schaub (editores), Lois, justice, coutume. Amériques et Europe latines (16e-19e siècles) (Paris, Francia: École des hautes études en Sciences Sociales, 2005). Así como textos más recientes, producto del proyecto State Building in Latin America: Juan Carlos Garavaglia y Pierre Gautreau (editores), Mensurar la tierra, controlar el territorio. América Latina. Siglos XVIII-XIX (Rosario, Argentina: Prohistoria. Ediciones, 2011); Juan Carlos Garavaglia, Juan Pro Ruíz y Eduardo Zimmermann (editores), Las fuerzas de guerra en la construcción del Estado. América Latina, siglo XIX (Rosario, Argentina: Prohistoria Ediciones, 2012); Juan Carlos Garavaglia y Juan Pro Ruíz (editores), Latin American Bureaucracy and the State Building Process (1780-1860) (Newcastle, Inglaterra: Cambridge Scholars, 2013); Juan Carlos Garavaglia y Claudia Contente (editores), Configuraciones estatales, regiones y sociedades locales: América Latina, siglo XIX-XIX (Barcelona: Ediciones Bellaterra, 2011), en: https://www.academia.edu/20321928/Configuraciones estatales regiones y sociedades_locales. Am\%C3Arica_Latina siglos_XIX-XX. Entre otros muchos más que han permitido importantes discusiones sobre los más variados temas.

29 Fradkin y Gelman, “Juan Carlos...", 18. 
un énfasis importante en la historia como problema para el futuro de las sociedades latinoamericanas. Su aproximación, influida por el contexto en el cual se formó, en las décadas de 1960 y 1970, demuestra una agenda muy variada y compleja, que muchas veces parece ser caprichosa, pero que se encontraba perfectamente guiada por una línea clara de investigación, como demuestra Raúl Fradkin. Es tal vez una de las mejores lecturas sobre el trabajo de Juan Carlos y nos orienta a través de su producción, según Fradkin -me permito reproducir en extenso este texto por la maravillosa lectura que hace el autor-:

\begin{abstract}
"[...] una pregunta resulta insoslayable: ¿qué era lo que unía el estudio del comercio, la yerba mate, el trigo y el maíz, a Yapeyú, Tepeaca y Areco, los ponchos, los ganados, los mercados, las relaciones de producción, las tecnologías, la agrimensura, los ecosistemas, la fiscalidad, la demografía, la formación de los estados y las naciones, los rituales, la justicia, los pueblos, la guerra o la política? ¿Es posible reconocer un "gran tema" que los hilvanara? Cada vez que se lo pregunté, solo me respondía: "una cosa te lleva a la otra". Pero desde mi punto de vista sí tuvo un "gran tema": la historia de los campesinos latinoamericanos y con ellos, las historias de los hombres y las mujeres del común". ${ }^{30}$
\end{abstract}

“¡¿Pero qué aparato?!, ¿dónde está ese aparato? ¡Personas! Eso es lo que hay", ${ }^{31}$ nos decía entre mil gestos con las manos, en una de las constantes reuniones que realizaba para guiar y criticar los resultados de investigación del equipo que había reunido en Barcelona. Parte de un esfuerzo para comprender la formación del Estado latinoamericano, usando la fiscalidad como enfoque. No en vano, su conclusión era que el Estado era un entramado de relaciones sociales de dominación, una definición que había hecho patente en otros trabajos anteriores. ${ }^{32} \mathrm{Y}$ que ahora buscaba evidenciar el elemento relacional de la construcción de las instituciones de Estado, eligiendo, no menos, un acercamiento amplio a la fiscalidad como un fenómeno en el cual podía verse la cotidianidad, los problemas y las relaciones de poder en la conformación de dicho espacio. ${ }^{33}$

$\mathrm{Su}$ esfuerzo se basaba en una crítica constante de las conclusiones del sentido común, profundamente enraizadas en la historia nacional. Argentina, ${ }^{34}$

30 Fradkin, "Indicios y conjeturas...", 259.

31 Es una anécdota, esto también se tradujo en su trabajo directamente: “...resulta evidente que el Estado no es una cosa o un 'aparato' - como solemos decir por comodidad, recogiendo así la tradición althuserianasino una relación social de dominación”. Garavaglia, Poder, conflicto..., 9.

32 Esta conclusión ya era evidente en sus trabajos de la década de 1990, no obstante, aparece explícita en su trabajo: Juan Carlos Garavaglia, Construir el Estado, inventar la nación. El Río de la Plata, siglos XVIII-XIX (Buenos Aires, Argentina: Prometeo Libros, 2007).

33 Para ello planteaba una frase de Schumpeter, "nada muestra tan claramente el carácter de una sociedad y de una civilización como la política fiscal adoptada por sus gobernantes, podemos esperar que en este campo se revelen con particular claridad la corriente principal y la contracorriente del período que estudiamos". Joseph A. Schumpeter, Historia del análisis económico (Barcelona, España: Editorial Ariel, 1994): 844.

34 Debo recordar en este momento la absoluta incredulidad y hasta enojo que se veía en la cara de Gara cada vez que leía o escuchaba a algún investigador hablar de algo llamado Argentina como una construcción 
sostenía, solo puede comprenderse en su dimensión latinoamericana, una de las banderas de su lucha como historiador, algo de lo que se enorgullecía. "Decían que había gauchos, tipos rudos que andaban por la campaña a caballo, pero $¿$ de dónde salían esos tipos rudos?, ¿de hoyos en la tierra? ¡No!, ¡eran campesinos ni más ni menos! Tipos que iban con sus familias". ${ }^{35}$ Esta anécdota plantea una conclusión, muy influida de su trabajo a lo largo de las décadas, es una lección en sí misma: las historiografías nacionalistas producen una profunda miopía analítica, que nos impide llegar a conclusiones más significativas, necesitamos crear preguntas más generales que sirvan para comprender fenómenos en el espacio latinoamericano.

"Conocer el lugar del que se habla o sobre el que se oye es fundamental, de qué otra manera te podés imaginar lo que pasaron las personas, de qué otra manera ubicás los problemas que afrontaron", era una idea que nos transmitía cada vez que íbamos a un congreso o taller en algún país de América Latina. Su aproximación a las personas estaba acompañada de una perspectiva que tendía siempre a reducir la escala de análisis, aun ante fenómenos inmensos, como el Estado. Esta característica, sin duda fue influida por su contacto con su maestro en París, Ruggiero Romano.

Jorge Gelman lo ha planteado claramente, al señalar que la formación de Juan Carlos, pasada por la profunda influencia de los Annales y los marxistas británicos e italianos, lo que lo llevó a aproximarse a la comprensión de las realidades sociales desde la perspectiva del ámbito material de la vida, pero con un enfoque particular. En ese sentido si Carlos Sempat Assadourian:

\footnotetext{
"fue quien propuso más acabado y brillantemente un modelo alternativo para entender el funcionamiento de la economía colonial, contrapuesto tanto al anacrónico de Mitre-Levene, como al de los dependentistas [...], Juan Carlos fue el primero en llevar ese programa enorme de investigaciones que se derivaba de ese modelo $-\mathrm{y}$ de los consejos de Ruggiero- a la práctica" ${ }^{36}$
}

El mismo Gelman ha señalado una de las características más relevantes de su proceder metodológico, derivado de los consejos de Ruggiero Romano: la constante tendencia de Juan Carlos a estudiar la historia desde los márgenes. Donde el análisis de pueblos o espacios aparentemente poco importantes podía devolver piezas de información clave. No era el análisis del oro y los grandes movimientos comerciales, sino de los pequeños productos de los mercados lo que podía generar información generalizable. En ese sentido, el estudio del

venida del fondo de los tiempos.

35 Se trata de una anécdota que nos relató Juan Carlos.

36 Gelman, "Juan Carlos...", 283. Tanto Gelman, como Carlos Marichal y Raúl Fradkin coinciden en rescatar también la influencia de figuras claves en la juventud y formación de Juan Carlos tales como Juan Arico. 
municipio de Tepeaca, en México, se transformó en un ejemplo de su proceder. ${ }^{37}$ Se pregunta Gelman, ¿por qué Tepeaca y no Potosí?, la respuesta se presentaba obvia, "mercados como Potosí había contados con los dedos de la mano, pero 'Tepeacas' había centenares". ${ }^{38}$

Como señala Carlos Marichal, la "profundidad de la reconstrucción del comercio, la agricultura, los telares y las haciendas, por medio de un gran cúmulo de testamentos, documentos eclesiásticos y civiles, revela una sociedad por demás compleja y en proceso de cambio tanto económico como social". ${ }^{39}$ Este proceder en su acercamiento a su objeto de estudio, la riqueza de su análisis y la más profunda $\mathrm{y}$, si me permiten, ridículamente impresionante vastedad de su manejo de fuentes, fue un sello de su trabajo, que se hace evidente, por ejemplo, en su libro sobre San Antonio de Areco de 2010. ${ }^{40}$ Una obra que, a mi parecer, sintetiza de manera maravillosa la metodología, las herramientas y el pensamiento de Juan Carlos desarrollados a lo largo de más de 40 años -hasta la publicación del libro de Areco- de labor como historiador en Argentina, México, Francia y España.

\section{Aportes del historiador: debates para Costa Rica}

Hasta ahora hemos repasado de la manera más breve la vida de una gran persona, que logró su meta de transformarse en un gran historiador, no solo dedicarse a la historia. Por sí sola su vida, cargada de un profundo compromiso social, político y académico es una lección suficiente para las nuevas generaciones de historiadores en toda América Latina. Su enfoque de análisis permite comprender los más complejos procesos sociales, estudiándolos desde los márgenes, con una escala reducida, de la mano de un manejo teórico y empírico impresionante. Sus estudios abrieron temáticas todavía inacabadas, algunas de las cuales apenas han sido exploradas.

Tan solo esa sucinta caracterización de Juan Carlos Garavaglia debería ser suficiente como lección para la historiografía costarricense. Pero si se me permite, he de escribir unas líneas sobre lo que podría aportar su trabajo, en términos de una nueva agenda historiográfica, de cara al bicentenario de la independencia en la región centroamericana. Ya que, como se ha señalado previamente, hay una serie de críticas e insinuaciones en el trabajo de Juan Carlos que podrían ser de gran utilidad. Este es un análisis que no se aparta de una lectura personal, parte de una invitación a los historiadores del país para renovar los estudios de historia política y económica de la colonia y del siglo XIX.

37 Véase Garavaglia y Grosso, Puebla desde una perspectiva microhistórica...

38 Gelman, “Juan Carlos...”, 285.

39 Marichal, 3.

40 Juan Carlos Garavaglia, San Antonio de Areco (1680-1880). Un pueblo de la campaña, del Antiguo Régimen a la modernidad argentina (Rosario, Argentina: Prohistoria Editores, 2009). 
La clave de esta discusión está en la comprensión del trabajo que Juan Carlos Garavaglia desarrolló en la última década de su vida. Pero que, como lo ha apuntado Darío Barriera, comenzó a perfilarse en sus años en la EHESS, desde $1991{ }^{41}$ La orientación de estos años se relacionó con la necesidad de reflexionar sobre el poder, vinculándolo con aquella conflictividad y las relaciones sociales que Juan Carlos había estudiado entre los campesinos de la campaña bonaerense y de Tepeaca, y que finalmente se sintetizó en el análisis de la población de San Antonio de Areco. En otras palabras, algo que ya hemos mencionado, su interés siempre presente por ver el funcionamiento más cercano de las relaciones sociales, que eran en última instancia las que daban forma a las instituciones.

Sus últimos trabajos estaban orientados a la comprensión de las dinámicas del Estado para caracterizar dos de sus principales instituciones: el ejército -las fuerzas de guerra y la represión, así como la justicia-y el financiamiento la fiscalidad-. No obstante, este interés era motivado por comprender al Estado como un entramado de relaciones sociales, donde "los hombres encarnan en forma concreta esas relaciones de dominación". ${ }^{42}$ Lo que indicaba un interés claro por rescatar las formas cotidianas de actuación de las personas comunes, que sintetizaban tradiciones políticas y espacios -institucionales e institucionalizados- donde se reproducía el poder en la sociedad a través de rituales. Como indica Barriera, sobre el trabajo de Juan Carlos, a propósito de la ritualización del poder en las etapas tempranas de la formación del Estado, iniciando el proceso independiente:

\footnotetext{
"esa selva de símbolos de la cual la institución es productora, pero también expresión, no es una inmóvil estructura que se expresa reiteradamente -la obra de teatro- a través de rituales - su puesta en escena-, sino que los mismos rituales están vivos, y la razón es que en el centro del foco siempre están los actores y sus conflictos -que pertenecen, claro está, al orden de la acción-".43
}

Tal vez la clave para entender la propuesta que se hace en estas últimas páginas, es señalar que para Juan Carlos era necesario poner en duda la construcción misma de esa "modernidad", que muchos autores han sostenido como parte de la construcción de una historia nacional, que limita la comprensión de las profundas interacciones sociales que eran parte de la política y la economía, pero también del pensamiento. Desde esta perspectiva la formación del Estado es más que solo el surgimiento y perfeccionamiento de instituciones y la desaparición de la mal llamada "herencia colonial". Los jueces de paz de Areco

41 Barriera, 211. Un trabajo que muestra este interés está en: Juan Carlos Garavaglia, "Paz, orden y trabajo en la campaña: la justicia rural y los juzgados de paz en Buenos Aires, 1830-1852", Desarrollo Económico (Argentina) 37, n. 146 (1997): 241-262.

42 Garavaglia, Poder, conflicto..., 9.

43 Barriera, 213. 
eran más que funcionarios - un término que no convencía mucho a Garavaglia-, eran mediadores en el espacio social de la campaña, entre el poder político y los campesinos, actuando tanto bajo las leyes que pretendían la modernización como bajo la costumbre, que poseía sus propias normas - la mayoría no escritas-. No se encontraban separados del mundo social en el que se desenvolvían, por lo que eran una fuente importante de conciliación y conexión entre modernidad y costumbre local. ${ }^{44}$

"[...] la pregunta que deberíamos hacernos aquí es la siguiente: ¿estamos frente a una concepción de la representación de tipo 'moderno' o 'antiguo'? En realidad -y ello no debería extrañarnos- estamos a mitad de camino entre una noción que se aproxima a la definición tradicional que dan los diccionarios hispanos del siglo XVII-XVIII y las concepciones de la teoría de la representación, tal como podemos verla en la Encyclopédie, por ejemplo". ${ }^{45}$

Nos aventuramos, en ese sentido, a señalar lo que ya ha sostenido José Carlos Chiaramonte, ${ }^{46}$ cuando propone la importancia de la "antigua constitución" como un concepto que incorpora tanto la costumbre como las normas antiguas en un conjunto coherente, que sirvió de marco de referencia a las relaciones sociales en el contexto de la transformación de las sociedades del siglo XIX en América Latina. Estos representantes del poder estaban enclavados entre dos marcos epistemológicos, uno que pretendía una cierta modernidad de orientación europea y otro que sostenía una costumbre construida a lo largo de siglos.

La historia nacional y las formas en que se ha comprendido la independencia, como acontecimiento y no como proceso, ${ }^{47}$ nos ha legado una tara analítica al crear una especie de barrera imaginaria pero potente, un mito historiográfico que sostiene la división irreconciliable entre "modernidad" y "colonia", definiendo ambos espacios de manera tajante y reduciendo a la última a la categoría de herencia y tradición arcaica -casi oscurantista-. Problema que es amplificado por la incapacidad de la mayor parte de la historia en la región centroamericana, como disciplina, de establecer vínculos reales que permitan una agenda

44 Algo que está relacionado con el pensamiento de Bourdieu, a quien utilizaba de manera constante como inspiración en sus discusiones, específicamente a las Razones prácticas de ese autor. Ver Pierre Bourdieu, Razones Prácticas. Sobre la teoría de la acción (Barcelona, España: Anagrama, 2002).

45 Garavaglia, San Antonio..., 406-407.

46 José Carlos Chiaramonte, "La antigua constitución luego de las independencias (1808-1852)", Desarrollo Económico (México) 50, n. 199 (2010): 331-361, en: https://www.academia.edu/31739914/ The_Ancient_Constitution_after_Independence_1808_1852_.

47 Hacer esta distinción implica señalar que la firma del acta es solo un acontecimiento que refleja el acto performativo que materializa el deseo de los cabildos por iniciar el proceso de conseguir la independencia efectiva y además un grado de autonomía, pero todavía indeterminada. No es el motivo de este artículo entrar en esta discusión, sino mencionar y dejar claro que hay una diferencia sensible entre emancipación, independencia y autonomía y que dicha diferencia puede generar una discusión de mucho valor que pondría en nueva perspectiva la idea del estudio de la independencia. 
de carácter regional, que planteen problemas más generales y, por lo tanto, más valiosos para la resolución de grandes preguntas en la construcción de nuestras sociedades. El campo de estudio del Estado debe superar el nivel institucional, así como los supuestos de la historia nacional, para construir una nueva alternativa de aproximación al poder como un espacio relacional en las sociedades del siglo XIX, que se libere de las restricciones de la modernidad como modelo de formación estatal. 